\title{
Diplomasi Indonesia dalam Menyelesaikan Krisis Pengungsi Rohingya Tahun 2017
}

\author{
Fuat Albayumi, Nourma Meysita Hadi, Djoko Susilo \\ Jurusan Hubungan Internasional, Universitas Jember, Jawa Timur - Indonesia \\ Email: fuat@unej.ac.id \\ Diserahkan 09 Juli 2018 | Diterima: 04 Oktober 2018
}

\begin{abstract}
The armed conflict in Rakhine in 2017 caused a humanitarian crisis for the Rohingyas. This crisis resulted in the emergence of criticism towards Myanmar government for its refusal to offer humanitarian assistance to the victims of conflict. In spite of that, the Myanmar government has closed access for foreigners, including humanitarian aid. However, Indonesia have accepted to discuss the settlement of the case. This research will examine how Indonesia's diplomacy to resolve the crisis due to the conflict in Rakhine in 2017. This research uses research literature method to collect secondary data coming from reliable source. This research is using qualitative descriptive technique and analyzed to described or interpreted to obtain a complete picture of the answer to the problem under study. The results show that in resolving the crisis for Rohingya ethnic in 2017, Indonesia conducts humanitarian diplomacy, which includes communicating with the Myanmar and Bangladesh governments and foreign parties, acting as a liaison between the Myanmar government and the international community, and negotiating with Myanmar and Bangladesh governments regarding the settlement of the Rohingya refugee crisis.
\end{abstract}

Keywords: Myanmar, Refugees, Rohingya, Indonesian, Diplomacy.

\begin{abstract}
Abstrak
Penelitian ini membahas tentang konflik bersenjata di Rakhine pada tahun 2017 yang menyebabkan krisis kemanusiaan bagi etnis Rohingya. Peristiwa ini berdampak terhadap munculnya kecaman terhadap pemerintah Myanmar atas penolakannya terhadap tawaran bantuan kemanusiaan bagi korban konflik. Pemerintah Myanmar justru menutup akses bagi pihak asing dalam bantuan kemanusiaan. Namun, Indonesia justru diterima oleh Myanmar untuk membicarakan penyelesaian kasus ini. Bagaimana langkah-langkah diplomasi Indonesia dalam menyelesaikan krisis pengungsi Rohingya akibat konflik di Rakhine pada tahun 2017 merupakan pokok permasalahan dalam penelitian ini. Penelitian ini menggunakan metode literature research yang bersumber dari media cetak, situs internet atau website resmi, buku cetak maupun elektronik, serta jurnal ilmiah. Analisis data dilakukan dengan teknik deskriptif kualitatif; data yang diperoleh dianalisis, kemudian diinterprestasikan untuk memperoleh gambaran secara utuh jawaban atas permasalahan yang diteliti. Hasil penelitian menunjukkan bahwa dalam menyelesaikan krisis kemanusiaan bagi etnis Rohingya tahun 2017, Indonesia melakukan diplomasi kemanusiaan yang meliputi; melakukan komunikasi dengan pemerintah Myanmar dan Bangladesh, bertindak sebagai penghubung antara pemerintah Myanmar dengan masyarakat internasional, serta melakukan negosiasi dengan pemerintah Myanmar dan Bangladesh terkait penyelesaian krisis pengungsi Rohingya.
\end{abstract}

Kata Kunci: Myanmar, Pengungsi, Rohingya, Diplomasi, Indonesia.

\section{PENDAHULUAN}

Krisis pengungsi Rohingya pada dasarnya

merupakan krisis

kemanusiaan yang dialami oleh etnis Rohingya akibat konflik yang terjadi di 
Myanmar. Konflik yang kerap terjadi di Myanmar antara etnis Rohingya dengan pemerintah Myanmar mengakibatkan krisis pengungsi bagi penduduk Rohingya. Situasi yang tidak aman ketika konflik menyebabkan penduduk Rohingya terpaksa melakukan eksodus ke negara lain, seperti yang terjadi pada konflik yang terjadi di wilayah Rakhine pada bulan Agustus 2017, ketika kelompok ARSA (Arakan Rohingya Salvation Army) menyerang pangkalan militer Myanmar di wilayah Rakhine. Peristiwa penyerangan ini berlanjut pada aksi kekerasan yang dilakukan oleh militer Myanmar terhadap etnis Rohingya. Konflik yang pecah pada tanggal 25 Agustus 2017 ini kemudian berlanjut pada aksi pembakaran perkampungan yang menjadi tempat tinggal etnis Rohingya. Untuk menghindari kekerasan yang terjadi, etnis Rohingya melarikan diri ke negara lain untuk mencari perlindungan.

Sebagai negara yang paling dekat dengan wilayah Rakhine, Bangladesh menjadi negara tujuan utama para pengungsi Rohingya. Ketika para pengungsi Rohingya mencari perlindungan ke Bangladesh, pemerintah Bangladesh justru menolak kehadiran mereka. Para pengungsi terlantar di perbatasan Bangladesh dengan kondisi kelaparan, tanpa jaminan kesehatan dan keamanan bahkan tak sedikit dari mereka yang meregang nyawa. Hal inilah yang kemudian menyebabkan terjadi krisis kemanusiaan bagi pengungsi Rohingya, di mana mereka tidak dapat memperoleh hak-hak dasarnya sebagai manusia. Hak-hak dasar tersebut antara lain; hak untuk hidup, hak memperoleh perlindungan dan rasa aman, hingga hak memperoleh keadilan untuk memperjuangkan hidupnya. Pemerintah Myanmar yang kurang serius dalam mengatasi krisis kemanusiaan ini menyebabkan konflik komunal berkepanjangan yang seakanakan memang sengaja diciptakan dengan tujuan untuk membersihkan etnis Rohingya itu sendiri.

Pasca terjadinya konflik yang terjadi di Rakhine pada tahun 2017, muncul banyak respon dari masyarakat internasional, baik dari organisasi internasional maupun negara-negara lain. Respon yang ditunjukkan bervariasi mulai kecaman keras terhadap pemerintah Myanmar bantuan kemanusiaan etnis Rohingya. Namun sayangnya pemerintah Myanmar pasca kejadian ini justru menutup akses bagi pihak asing (Arungbudoyo, 2017). Hal ini menyebabkan masyarakat internasional tidak bisa mengirimkan bantuan kemanusiaan bagi korban konflik. Selain itu juga pemerintah Myanmar sangat membatasi liputan 
media, baik media lokal maupun asing, sehingga masyarakat internasional menjadi kesulitan untuk memperoleh informasi akurat yang mengakibatkan kesimpang-siuran informasi yang beredar tidak bisa dihindari.

Di tengah sikap Myanmar yang memblokir akses pihak asing, Indonesia melakukan kunjungan diplomatik ke Myanmar. Kunjungan ini khusus dilakukan untuk melakukan dialog dengan otoritas Myanmar guna membahas solusi atas permasalahan ini. Kunjungan Indonesia ke Myanmar pasca konflik di Rakhine pada tahun 2017 mendapat apresiasi dari masyarakat internasional, karena Indonesia merupakan negara pertama yang mengunjungi Myanmar pasca terjadinya konflik tersebut (DW, 2017).

Kunjungan diplomatik Indonesia ke Myanmar untuk melakukan dialog dengan pemerintah Myanmar ini tidak mungkin terlaksana apabila pemerintah Myanmar tidak memberi akses kepada Indonesia. Akses tersebut tidak diberikan apabila tidak adanya kepercayaan dari pemerintah Myanmar terhadap Indonesia. Langkah-langkah diplomasi yang dilakukan Indonesia dalam menyelesaikan krisis pengungsi Rohingya akibat konflik yang terjadi di Rakhine pada tahun 2017 dan capaian diplomasi Indonesia dalam menyelesaikan krisis pengungsi
Rohingya tahun 2017 merupakan pokok permasalahan yang dibahas dalam karya ilmiah ini.

\section{KERANGKA TEORITIK}

Dalam penelitian ini digunakan konsep diplomasi kemanusiaan. Minear dan Smith (2007) menjelaskan bahwa secara konseptual diplomasi dan kemanusiaan merupakan hal yang berbeda. Diplomasi selama ini dipahami sebagai upaya untuk mengedepankan kepentingan nasional dengan cara apapun, sedangkan kemanusiaan mengacu pada nilai-nilai, prinsip dan norma internasional yang diakui secara universal. Sederhananya, kemanusiaan tidak terhalang oleh batas-batas kekuasaan suatu negara, sedangkan diplomasi terikat oleh kekuasaan pemerintah.

Aktor

kemanusiaan melaksanakan tugas mereka dengan memperhatikan hukum humaniter internasional, dengan kontribusinya sebatas pemberian bantuan berupa hak-hak dasar kemanusiaan kepada korban konflik, seperti hak untuk hidup, makan, tempat tinggal dan kesehatan. Sebaliknya, aktor diplomasi atau diplomat, tugas mereka meliputi aktivitas politik menyangkut kepentingan nasional yang meliputi urusan hubungan luar negeri. Perpaduan dua konsep ini menghasilkan pemahaman bahwa diplomat kemanusiaan hadir bukan 
sebagai advokat politik, tetapi sebagai negosiator politik (Minear dan Smith, 2007, 50).

\section{Diplomasi kemanusiaan} umumnya tidak mengandalkan penggunaan kekuatan untuk mencapai tujuan. Penggunaan kekuatan atau ancaman penggunaan kekuatan (coercive diplomacy) dianggap tidak efisien untuk dijadikan sebagai instrumen diplomasi kemanusiaan. Instrumen tersebut dianggap kurang tajam untuk digunakan sebagai cara mencapai tujuan diplomasi kemanusiaan. Intervensi kemanusiaan merupakan kegagalan diplomasi kemanusiaan, karena tujuan diplomasi kemanusiaan hampir dapat dikatakan telah dicapai jika kekuatan militer tidak digunakan untuk membunuh, melukai dan merusak kehidupan manusia.

Dalam melakukan diplomasi kemanusiaan, ada beberapa proses yang dapat dilakukan, meliputi; pengumpulan informasi, komunikasi dan negosiasi (Minear \& Smith, 2007, 54). Dalam pengumpulan informasi aktor diplomasi kemanusiaan perlu mengumpulkan informasi yang dapat dipercaya dari negara tuan rumah (yang berkonflik) untuk dua tujuan: pertama, agar mampu melaksanakan program dan kegiatan mereka secara efisien. Kedua, untuk bertanggung jawab kepada pihak - pihak yang turut membantu tentang bagaimana mereka menggunakan dana yang dialokasikan.
Melalui proses pengumpulan informasi ini, informasi yangdiperoleh aktor diplomasi kemanusiaan bukan hanya bermanfaat bagi pihak - pihak yang turut membantu, tetapi juga sebagai akses bagi pihak internasional lain untuk menjadi satu - satunya sumber informasi yang dapat dipercaya. Oleh karena itu, aktor diplomasi kemanusiaan yang dipercaya tersebut memiliki akses istimewa di negara tuan rumah.

Aktor diplomasi kemanusiaan melakukan komunikasi antara pemerintah negara tuan rumah dengan kantor pusat aktor diplomasi kemanusiaan tersebut berasal, untuk pengumpulan informasi. Aktor diplomasi kemanusiaan bekerja secara fisik dan politik di zona konflik yang sulit dan berbahaya. Kehadiran mereka sangat bermanfaat untuk mengaktifkan komunikasi politik yang diperlukan antara aktor-aktor yang berkonflik, karena sering kali konflik terjadi akibat arus komunikasi yang tidak lancar hingga menyebabkan miss communication.

Perundingan atau negosiasi adalah proses terakhir dari diplomasi kemanusiaan. Aktor diplomasi kemanusiaan melakukan negosiasi untuk mencapai tujuan kemanusiaan. Kesepakatan dicapai dengan menggunakan instrumen diplomatik klasik seperti persuasi, janji dan dialog. Berdasarkan konsep kemanusiaan dan 
konsep diplomasi yang telah dipaparkan sebelumnya, diplomasi kemanusiaan dapat menjadi jembatan antara kepentingan nasional dan kepentingan internasional. Diplomasi kemanusiaan bukan berarti mengesampingkan kepentingan nasional, namun tujuan terpenting yakni bagaimana kepentingan nasional yang ada dapat selaras dengan prinsipprinsip moral universal. Aktor kemanusiaan dapat terlibat dalam proses diplomasi, tetapi mereka harus sangat berhati - hati dalam membedakan informasi untuk tujuan kemanusiaan. Mereka juga harus berhati-hati dalam peran sebagai komunikator, untuk tidak masuk lebih dalam ke dalam urusan politik negara tuan rumah yang sedang berkonflik.

\section{METODE PENELITIAN}

Penelitian ini menggunakan metode literature research untuk memperoleh data sekunder yang diperoleh dari media cetak, situs internet atau website resmi, buku cetak maupun elektronik (e-book), serta jurnal ilmiah. Data yang diperoleh kemudian dianalisis dengan teknik analisis deskriptif kualitatif. Data-data tersebut dianalisis, kemudian dideskripsikan atau diinterprestasikan untuk memperoleh gambaran secara utuh jawaban atas permasalahan yang diteliti.

\section{HASIL DAN PEMBAHASAN}

Hasil penelitian menunjukkan bahwa dalam menyelesaikan krisis pengungsi Rohingya tahun 2017, Indonesia melakukan diplomasi kemanusiaan yang meliputi; Mediasi dengan Pemerintah Myanmar dan Bangladesh serta beberapa pihak asing, Mediasi antara pemerintah Myanmar dan masyarakat internasional, serta melakukan negosiasi dengan pemerintah Myanmar dan Bangladesh terkait solusi penyelesaian krisis pengungsi Rohingya.

\section{Mediasi Indonesia dengan Pemerintah Myanmar, Bangladesh dan Pihak Asing}

Dalam memulai perannya untuk menyelesaikan krisis kemanusiaan di Rohingya Indonesia menjalin komunikasi dengan Myanmar dan Bangladesh, serta beberapa pihak asing. Komunikasi ini bertujuan untuk membicarakan kondisi terkini di Rakhine serta mendiskusikan solusi untuk mengatasi kasusini. Pihak-pihak asing tersebut antara lain Perserikatan Bangsa-Bangsa (PBB), Dewan Penasihat Rohingya dan Organisasi Kerjasama Islam (OKI) (Iqbal, 2017).

Pada tanggal 29 Agustus 2017, Indonesia yang diwakili oleh Menteri Luar Negeri Retno Marsudi menjalin komunikasi via telepon dengan Myanmar yang diwakili oleh ketua National Security Advisor (NSA) yakni 
Thaung Tun. Dalam komunikasi ini, Indonesia dan Myanmar membahas situasi terkini di Rakhine. Sedangkan dengan Bangladesh, Menteri Luar Negeri Indonesia Retno Marsudi menjalin komunikasi dengan Menteri Luar Negeri Bangladesh Abul Hassan Mahmud Ali. Dalam kesempatan tersebut, Indonesia membicarakan krisis pengungsi Rohingya dan meminta Bangladesh dan Myanmar melakukan dialog terkait solusi atas krisis pengungsi Rohingya (Ihsanuddin, 2017).

Indonesia juga menjalin komunikasi dengan Dewan Penasihat Rohingya. Kofi Annan sebagai ketua Dewan Penasihat Rohingya melakukan percakapan via telepon dengan Menteri Luar Negeri Indonesia Retno Marsudi pada malam hari tanggal 29 Agustus 2017. Dalam percakapan tersebut, Kofi Annan memberi mandat kepada Indonesia untuk membujuk Myanmar agar melaksanakan laporan rekomendasi solusi atas krisis kemanusiaan etnis Rohingya dari Dewan Penasihat Rohingya yang dipimpin oleh Kofi Annan.

Indonesia juga menjalin komunikasi dengan Turki yang saat itu menjabat sebagai ketua Organisasi Kerjasama Islam (OKI). Pada tanggal 30 Agustus 2017, Menteri Luar Negeri Turki Mevlut Cavusoglumenghubungi Menteri Luar Negeri Indonesia Retno
Marsudi untuk menanyakan kondisi terkini di Rakhine, mengingat Indonesia telah menjalin komunikasi sebelumnya dengan perwakilan pemerintah Myanmar. Pada kesempatan ini pula, Indonesia dan Turki mendiskusikan solusi untuk menyelesaikan krisis kemanusiaan ini (Iqbal, 2017).

Pada tanggal 1 September 2017, Indonesia menjalin komunikasi dengan PBB. Dalam aktivitas tersebut, Indonesia yang diwakili oleh Menteri Luar Negeri Indonesia Retno Marsudi melakukan komunikasi dengan Sekjen PBB Antonio Gutteres melalui telepon. Dalam komunikasi tersebut, mereka membicarakan perkembangan yang terjadi di Rakhine pasca konflik. Pada kesempatan tersebut Sekjen PBB menyatakan harapannya kepada Indonesia untuk bisa menyelesaikan kasus ini (Iqbal, 2017).

Sebagai tindak lanjut dari komunikasi yang telah dilakukan selanjutnya, Menteri Luar Negeri Indonesia Retno Marsudi melakukan kunjungan ke Myanmar pada tanggal 4 September 2017 sebagai wujud simpati terhadap yang telah terjadi di Myanmar. Kunjungan ini juga secara khusus digunakan untuk membahas solusi terkait krisis pengungsi Rohingya yang menjadi korban atas konflik pada bulan Agustus 2017 (Kardi, 2017). Itikat baik Indonesia ternyata disambut dengan baik oleh 
pemerintah Myanmar, dengan bersedianya pihak otoritas tertinggi Myanmar dan panglima militer Myanmar untuk bertemu dengan Menteri Luar Negeri Indonesia yang berkunjung ke Myanmar (Tempo, 2017).

Selanjutnya pada tanggal 5 September 2017 Menteri Luar Negeri Indonesia mengunjungi Bangladesh. Hal ini dilakukan karena Bangladesh merupakan negara tujuan utama bagi pengungsi Rohingya, sementara Bangladesh menutup pintu perbatasannya bagi pengungsi Rohingya. Di Bangladesh, Menteri Luar Negeri Indonesia Retno Marsudi bertemu dengan Perdana Menteri Bangladesh Sheikh Hasina dan Menteri Luar Negeri Bangladesh yakni Mahood Ali. Dalam pertemuan tersebut Indonesia dan Bangladesh membicarakan kondisi terkini pengungsi Rohingya dan rencana pemberian bantuan kemanusiaan untuk pengungsi Rohingya di Bangladesh (Kardi, 2017).

Pada rangkaian perjalanan diplomatik yang dilakukan oleh Menteri Luar Negeri Retno Marsudi ke Myanmar dan Bangladesh pada tanggal 4 sampai 5 September 2017, Indonesia menyampaikan perlunya dialog antara Myanmar dan Bangladesh terkait krisis pengungsi Rohingya ini. Dialog ini perlu secepatnya dilakukan untuk mencari solusi terbaik bagi pengungsi
Rohingya. Perlunya komunikasi antara Myanmar dan Bangladesh juga untuk membicarakan bagaimana solusi permanen bagi etnis Rohingya. Dalam hal itu Indonesia menawarkan diri untuk menjadi 'jembatan' antara pemerintah Bangladesh dan Myanmar (Reuters, 2017). Tawaran pemerintah Indonesia tersebut dimaksudkan agar proses negosiasi antar kedua negara bisa berjalan dengan lancar, mengingat komunikasi antara Bangladesh dan Myanmar sedang tidak baik.

\section{Mediasi Indonesia dengan Pemerintah Myanmar dan Masyarakat Internasional}

Setelah melakukan komunikasi dengan berbagai pihak dan melakukan kunjungan langsung ke wilayah konflik, Indonesia telah mendapatkan informasi yang akurat mengenai situasi di Rakhine pasca konflik pada bulan Agustus 2017. Dari komunikasi tersebut, Indonesia mengetahui kondisi pengungsi Rohingya, serta mendapatkan kepercayaan pemerintah Myanmar. Dengan posisi demikian, Indonesia dapat bertindak selaku penyambung lidah bagi pemerintah Myanmar untuk berhubungan dengan masyarakat internasional. Misi Indonesia selanjutnya ialah untuk melakukan dialog dengan masyarakat internasional guna mencari solusi terbaik untuk menyelesaikan krisis pengungsi Rohingya. 
Untuk menyelesaikan krisis kemanusiaan yang menimpa pengungsi Rohingya, mustahil bagi Indonesia untuk berkerja sendiri. Untuk itu, sebagai penghubung antara pemerintah Myanmar dan masyarakat internasional, Indonesia secara aktif melakukan dialog dengan masyarakat internasional untuk menemukan solusi atas kasus ini. Dukungan dari ASEAN sangatlah diperlukan, mengingat ASEAN merupakan kawasan yang terdampak langsung atas terjadinya kasus ini. Pemerintah Indonesia terus berusaha meyakinkan negara-negara ASEAN lain untuk turun tangan mengatasi permasalahan ini. Pada forum pleno KTT ASEAN ke-31 di Filipina pada tanggal 13 November 2017, Presiden Joko Widodo telah menyinggung konflik yang terjadi di Rakhine (Jordan, 2017). Indonesia menjadi pelopor di antara negara negara ASEAN lain dalam mengatasi krisis kemanusiaan di Myanmar, dan mengharapkan partisipasi negara negara ASEAN lain dalam menyalurkan bantuan kemanusiaan.

Pada KT'T OKI di Kazakhstan tanggal 10 sampai 11 September 2017, Indonesia merupakan salah satu negara OKI yang terus mendorong negara-negara anggota OKI lainnya untuk melakukan tindakan nyata dalam membantu menyelesaikan krisis pengungsi Rohingya. Tindakan nyata yang diharapkan berupa pengiriman bantuan kemanusiaan dan dukungan kepada Indonesia untuk mendesak pemerintah Myanmar agar segera menyelesaikan krisis pengungsi Rohingya, dengan harapan dalam jangka panjang pemerintah Myanmar dapat segera menyelesaikan krisis kemanusiaan yang diderita oleh etnis Rohingya.

Setelah KTT OKI, pemerintah Indonesia menghadiri Sidang Umum PBB yang akan dilakukan mulai tanggal 12 September 2017 (Lestari, 2017). Indonesia bersama OKI, membawa kasus ini pada Sidang Umum PBB. Atas desakan Indonesia dan OKI, PBB membahas krisis pengungsi Rohingya yang diakibatkan oleh kekerasan yang terjadi di Rakhine pada akhir bulan Agustus 2017. Pada Sidang Umum lanjutan pada tanggal 24 Desember 2017, PBB mendesak Myanmar menghentikan operasi militer terhadap Rohingya. Kemudian OKI mengajukan resolusi terkait kasus kemanusiaan ini. Resolusi tersebut antara lain berisi; mendesak pemerintah Myanmar untuk membuka akses bantuan kemanusiaan dari pihak asing, memastikan keamanan pengungsi Rohingya untuk kembali ke Myanmar, dan memberikan hak kewarganegaraan penuh bagi etnis Rohingya (Tempo, 2017). Namun demikian upaya untuk mengeluarkan resolusi terkait krisis Rohingya ini gagal tercapai walaupun didukung oleh 
122 negara, tetapi ditolak oleh 10 negara, dan 24 negara lainnya abstain. Myanmar secara otomatis menolak resolusi ini. Cina dan Russia masih menjadi kawan setia Myanmar, dengan berada di pihak Myanmar yang menolak resolusi yang diusulkan OKI tersebut. Sedangkan negara lain yang menolak resolusi ini adalah; Kamboja, Laos, Vietnam, Filipina, Belarusia, Suriah, dan Zimbabwe (Teresia, 2017).

\section{Negosiasi Indonesia dengan Pemerintah Myanmar dan Bangladesh terhadap Krisis Pengungsi Rohingya}

Pada kunjungan diplomatik Indonesia ke Myanmar pada tanggal 4 September 2017, Indonesia dan Myanmar menegosiasikan solusi atas krisis kemanusiaan yang menimpa pengungsi Rohingya. Dalam pertemuan tersebut Indonesia menyampaikan solusi atas konflik yang terjadi di Myanmar. Solusi yang disampaikan Indonesia berisi lima elemen yang disebut Formula 4+1. Empat elemen tersebut terdiri dari; pertama, mengembalikan stabilitas dan keamanan, kedua yakni menahan diri secara maksimal dan tidak menggunakan kekerasan, ketiga yakni perlindungan kepada semua orang yang berada di Rakhine State tanpa memandang suku dan agama, dan keempat yakni pentingnya segera dibuka akses untuk bantuan kemanusiaan. Serta satu elemen terakhir ialah pentingnya agar rekomendasi Laporan Dewan Penasehat Rohingya pimpinan Kofi Annan dapat segera diimplementasikan. Dalam pertemuan tersebut Indonesia juga menyampaikan pentingnya komunikasi yang dilakukan oleh pemerintah Myanmar dan pemerintah Bangladesh (Kemlu, 2017). Dialog ini bertujuan untuk membicarakan solusi secara kongkrit bagi pengungsi Rohingya.

Dalam kunjungan Indonesia ke Myanmar tersebut, Indonesia melalui Menteri Luar Negeri Retno Marsudi juga menegosiasikan bantuan kemanusiaan yang bisa diberikan Indonesia kepada para korban konflik. Bantuan kemanusiaan tersebut bertujuan untuk meringankan penderitaan korban konflik serta meringankan beban pemerintah Myanmar sebagai penanggung jawab atas korban konflik yang terjadi di negaranya. Solusi yang diberikan Indonesia terkait dengan memberikan bantuan kemanusiaan bagi seluruh korban konflik, bantuan tersebut ditujukan bukan hanya terfokus untuk etnis Rohingya.

Sikap Indonesia yang tidak pandang bulu dalam membantu Myanmar, dengan memberi bantuan kemanusiaan ke semua korban konflik, semakin membangun kepercayaan pemerintah Myanmar terhadap 
Indonesia bahwa solusi yang diberikan Indonesia untuk membantu menyelesaikan krisis pengungsi Rohingya ini demi tujuan kemanusiaan. Selain pemberian bantuan kemanusiaan berupa kebutuhan pokok, yang menjadi highlight dalam kerjasama penyaluran bantuan kemanusiaan terhadap korban konflik ini ialah pembangunan rumah sakit di Rakhine.

Bantuan kemanusiaan tersebut diharapkan dapat digunakan sebagai media pemberdayaan masyarakat setempat, dan bersifat berkelanjutan. Dalam pertemuan tersebut Indonesia yang diwakili oleh Menteri Luar Negeri Retno Marsudi juga menyampaikan niat baik masyarakat internasional untuk ikut serta meringankan beban korban konflik. Untuk itu Indonesia juga mendesak pemerintah Myanmar segera membuka akses bantuan dari pihak asing agar segera dapat dilanjutkan (Detik, 2017).

Selain ke Myanmar, Menteri Luar Negeri Indonesia juga melakukan kunjungan diplomatik ke Bangladesh pada 5 September 2017 (CNN, 2017). Kunjungan diplomatik Indonesia ke Bangladesh ini bertujuan khusus untuk menegosiasikan solusi untuk menyelesaikan krisis kemanusiaan yang diderita oleh pengungsi Rohingya akibat konflik yang terjadi pada akhir bulan Agustus 2017. Dalam kunjungan diplomatik ini, Menteri Luar Negeri
Indonesia Retno Marsudi bertemu dengan Perdana Menteri Bangladesh Sheikh Hasina dan Menteri Luar Negeri Bangladesh Abul Hassan Mahmud Ali. Pada pertemuan ini, Indonesia membujuk Bangladesh agar mau menerima dan melindungi pengungsi etnis Rohingya (CNN, 2017).

Karena alasan utama Bangladesh menolak kehadiran pengungsi Rohingya adalah bahwa kamp pengungsi Rohingya sumbangan dari PBB sudah penuh akibat gelombang pengungsi sebelumnya, dan faktor ekonomi di mana Bangladesh merupakan negara miskin, maka dalam kunjungan tersebut Indonesia menawarkan solusi untuk membantu Bangladesh dalam mencukupi kebutuhan kemanusiaan bagi pengungsi Rohingya. Langkah serius Indonesia untuk menyalurkan bantuan kemanusiaan terhadap pengungsi Rohingya ialah dengan adanya dialog yang dilakukan dengan Badan Pengungsi PBB (UNHCR) dan Organisasi Migrasi Internasional (IOM) yang ada di Bangladesh. Jadi selain bertemu dengan Perdana Menteri Bangladesh dan Menteri Luar Negeri Bangladesh, pada kunjungan diplomatik Indonesia ke Bangladesh Indonesia juga melakukan negosiasi dengan UNHCR dan IOM yang ada di Bangladesh guna mendiskusikan solusi bagi pengungsi Rohingya. Sebagai 
tindak lanjut dari kunjungan diplomatik tanggal 5 September 2017, Duta Besar Indonesia di Bangladesh mengadakan pertemuan dengan Menteri Luar Negeri Bangladesh pada tanggal 6 September 2017 untuk menegosiasikan lebih lanjut bantuan yang dibutuhkan Bangladesh dalam menangani pengungsi Rohingya (CNN, 2017).

Pada pertemuan tersebut, Indonesia juga mengingatkan kembali tentang apa yang telah dibahas pada komunikasi sebelumnya antara Menteri Luar Negeri Indonesia Retno Marsudi dengan Menteri Luar Negeri Bangladesh Abul Hassan Mahmud Ali melalui sambungan telepon pada tanggal 29 Agustus 2017, mengenai pentingnya menjalin hubungan bilateral yang baik dengan Myanmar (Ihsanuddin, 2017). Hubungan bilateral yang baik antara Bangladesh dan Myanmar dapat mengaktifkan kembali komunikasi politik antar keduanya, karena dengan adanya komunikasi antara Bangladesh dan Myanmar inilah diharapkan muncul sebuah solusi akhir yang konkrit bagi krisis pengungsi Rohingya akibat konflik yang pecah pada akhir bulan Agustus 2017.

\section{Capaian Diplomasi Indonesia dalam Menyelesaikan Krisis Pengungsi Rohingya Tahun 2017}

Diplomasi kemanusiaan yang dilakukan Indonesia menghasilkan beberapa capaian penting dalam menyelesaikan krisis kemanusiaan yang dialami oleh etnis Rohingya. Capaian tersebut meliputi; Indonesia memperoleh informasi yang akurat terkait kondisi di Rakhine pasca konflik tahun 2017, Indonesia menjadi penghubung antara pemerintah Myanmar dan masyarakat internasional, pemerintah Myanmar dan Bangladesh melakukan pertemuan bilateral, dan implementasi formula 4+1 sebagai solusi penyelesaiaan krisis pengungsi Rohingya, serta bersedianya pemerintah Bangladesh memberi perlindungan kepada pengungsi Rohingya.

\section{Kondisi di Rakhine Pasca Konflik Tahun 2017}

Di tengah tekanan internasional terhadap pemerintah Myanmar terkait kasus ini, Indonesia hadir sebagai kawan lama Myanmar. Langkah pertama yang dilakukan Indonesia adalah melakukan komunikasi dengan pemerintah Myanmar dengan tujuan untuk mendapatkan informasi terkait kondisi terkini di Rakhine pasca terjadinya konflik. Komunikasi tersebut dilakukan melalui saluran telepon. Pada komunikasi melalui sambungan telepon tersebut, Menteri Luar Negeri Indonesia Retno Marsudi berkomunikasi dengan Ketua Myanmar National Security Advisor 
(NSA) yakni Thaung Tun pada tanggal 29 Agustus 2017 (Ihsanuddin, 2017). Dalam komunikasi tersebut Indonesia menyampaikan bahwa Indonesia akan terus memantau perkembangan situasi di Rakhine dan menyampaikan keprihatinan akan peristiwa yang terjadi di wilayah Rakhine. Indonesia menyampaikan kepada Dewan Penasihat Keamanan Nasional Myanmar untuk memberi perlindungan terhadap seluruh penduduk Rakhine, termasuk etnis Rohingya, untuk mencegah bertambahnya korban jiwa di kalangan warga sipil. Kemudian Thaung Tun merespon Indonesia dengan mengatakan bahwa situasi di Rakhine sangat kompleks terkait konflik tersebut (Ihsanuddin, 2017).

Perlindungan keamanan di wilayah Rakhine harus dilakukan secara inklusif kepada seluruh penduduk yang ada di Rakhine, mengingat konflik yang terjadi juga menyangkut ranah kemanusiaan. Kemudian atas dasar tersebut, Indonesia berinisiatif untuk melakukan komunikasi dengan Bangladesh terkait kebijakan negara tersebut yang menutup akses perbatasannya agar pengungsi Rohingya tidak dapat memasuki negaranya. Selain itu sebagai langkah lanjutan terkait misi diplomatiknya untuk membantu menyelesaikan krisis pengungsi Rohingya akibat konflik pada bulan Agustus 2017, Indonesia mengatur jadwal kunjungan diplomatik Indonesia ke Myanmar (Erdianto, 2017).

Indonesia melakukan komunikasi dengan Bangladesh untuk mengetahui kondisi pengungsi Rohingya yang terlantar di perbatasan Bangladesh. Kondisi ini diakibatkan oleh kebijakan Bangladesh yang menolak kehadiran para pengungsi Rohingya. Pada tanggal 29 Agustus 2017, Menteri Luar Negeri Indonesia Retno Marsudi menelpon Menteri Luar Negeri Bangladesh Abul Hassan Mahmud Ali untuk membahas masalah pengungsi tersebut. Indonesia mendorong pemerintah Bangladesh untuk ikut serta membantu menangani masalah pengungsi Rohingya. Sebagai langkah serius Indonesia untuk menyelesaikan krisis kemanusiaan yang dialami oleh para pengungsi Rohingya akibat konflik yang pecah pada bulan Agustus 2017, Indonesia bersedia untuk menjadi penghubung antara pemerintah Bangladesh dan pemerintah Myanmar (Ihsanuddin, 2017).

\section{Indonesia Menjadi Penghubung Pemerintah Myanmar dan Masyarakat Internasional}

Setelah melakukan komunikasi dengan pihak terkait, yakni pemerintah Myanmar dan pemerintah Bangladesh, baik melalui telepon maupun kunjungan langsung ke Myanmar dan 
Bangladesh, Indonesia telah memperoleh informasi yang akurat mengenai kondisi di wilayah Rakhine pasca terjadi konflik di wilayah tersebut pada akhir bulan Agustus 2017. Informasi tersebut sangatlah dibutuhkan bagi masyarakat internasional untuk meluruskan berita yang simpang siur pasca konflik tersebut, akibat kebijakan pemerintah Myanmar yang membatasi akses media massa baik lokal maupun internasional. Hal terpenting dari informasi terkini di wilayah Rakhine pasca konflik yang berhasil dikantongi Indonesia adalah untuk mengetahui dengan pasti bantuan kemanusiaan yang dibutuhkan oleh korban konflik.

Pada level internasional, Indonesia mendorong OKI untuk membawa kasus ini pada sidang umum PBB yang dilakukan mulai 12 September 2017 (Lestari, 2017). Akhirnya OKI membawa krisis kemanusiaan yang dialami oleh pengungsi Rohingya tersebut pada sidang umum PBB. Kemudian pada sidang umum lanjutan PBB pada tanggal 24 Desember 2017, PBB membahas kasus ini dalam forum tersebut (Teresia, 2017). Dalam forum lanjutan sidang umum PBB tersebut, OKI mengajukan resolusi untuk menyelesaikan krisis Rohingya. Namun resolusi PBB yang diusulkan OKI terkait kasus ini gagal dilakukan. Resolusi yang ditawarkan OKI tersebut didukung oleh 122 negara, ditolak oleh 10 negara, dan 24 negara lainnya abstain. Myanmar secara otomatis menolak resolusi ini. Cina dan Russia masih menjadi kawan setia Myanmar, dengan berada di pihak Myanmar yang menolak resolusi yang diusulkan OKI tersebut. Sedangkan negara lain yang menolak resolusi ini adalah; Kamboja, Laos, Vietnam, Filipina, Belarusia, Suriah, dan Zimbabwe (Teresia, 2017).

\section{Pertemuan Bilateral Myanmar dan Bangladesh}

Sebagai respon positif dari Bangladesh dan Myanmar terhadap dorongan Indonesia untuk melakukan pertemuan bilateral terkait krisis pengungsi Rohingya, kedua negara ini bersepakat untuk melakukan pertemuan bilateral untuk membahas persoalan tersebut. Pertemuan ini dilakukan di Myanmar pada tanggal 23 November 2017. Dalam negosiasi tersebut, dicapai kesepakatan pemulangan pengungsi Rohingya ke Myanmar. Kesepakatan ini diakui Myanmar berdasarkan pakta repatiasi antara Myanmar dan Bangladesh tahun 1992-1993 (Suryanto, 2017).

Dalam pertemuan tersebut disepakati tentang perjanjian repatriasi pengungsi Rohingya, dengan syarat pengungsi tersebut telah memenuhi verifikasi data dan dokumen. Myanmar juga bersedia menjamin keamanan 
pada proses repatriasi para pengungsi Rohingya yang memenuhi syarat verifikasi tersebut. Proses repatriasi disepakati mulai dilakukan pada bulan Januari 2018 (Perdana, 2017).

\section{Implementasi Formula 4+1 sebagai Solusi Krisis Pengungsi Rohingya}

Dalam kunjungan diplomatik Indonesia ke Myanmar pada tanggal 4 September 2017, Indonesia memberikan solusi penyelesaian kasus ini dengan formula 4+1. Untuk formula pertama hingga ketiga yang berfokus pada pengembalian kondisi stabil dan aman di wilayah Rakhine, serta pemberian perlindungan kepada semua orang yang berada di Rakhine tanpa memandang suku dan agama, Indonesia telah melakukan diskusi dengan Jendral senior U Min Aung Hlaing selaku otoritas militer Myanmar (Pratama, 2017). Sebenarnya kelima formula ini ditujukan kepada otoritas tertinggi Myanmar sebagai pemegang kendali atas segala kondisi di Myanmar, namun Indonesia lebih menekankan solusi terkait formula poin pertama hingga ketiga kepada Panglima Militer Myanmar karena merupakan pihak yang bertanggung jawab untuk menjaga stabilitas dan keamanan di Myanmar. Dalam diskusi tersebut Indonesia mengatakan bahwa situasi aman di Rakhine diperlukan agar proses penyaluran bantuan keamanan dan rehabilitasi terhadap korban konflik dapat dilakukan dengan lancar (Pratama, 2017).

Terkait solusi Indonesia yang tertuang dalam formula $4+1$ tepatnya pada poin ke empat, Indonesia juga menegosiasikan mekanisme penyaluran bantuan yang akan diberikan Indonesia kepada korban konflik. Komitmen Indonesia dalam membantu menyelesaikan krisis pengungsi Indonesia merupakan hasil kerjasama yang baik antara pemerintah Indonesia dan masyarakat Indonesia. Pada kesempatan tersebut Indonesia menyampaikan kepada Myanmar bahwa Indonesia telah membentuk sebuah aliansi khusus untuk mememberi bantuan kemanusiaan bagi korban konflik di Rakhine. Aliansi tersebut merupakan hasil sinergi dari pemerintah Indonesia dengan masyarakat Indonesia. Pemerintah Indonesia bekerjasama dengan beberapa lembaga swadaya masyarakat yang bergerak di bidang kemanusiaan. Gabungan lembaga swadaya masyarakat tersebut kemudian dinamakan AKIM (Aliansi Kemanusiaan Indonesia untuk Rohingya) yang diresmikan pada tanggal 31 Agustus 2017 oleh Kementerian Luar Negeri Indonesia (Maulana, 2017).

Dalam negosiasi tersebut dicapai kesepakatan akan dibukanya akses bantuan kemanusiaan bagi korban konflik oleh pemerintah Myanmar. 
Mekanisme penyaluran bantuan kemanusiaan ini akan dipimpin oleh Myanmar dan akan melibatkan ICRC (Komite Palang Merah Internasional) dan ASEAN (Kemlu, 2017). Pemerintah Indonesia dan AKIM bekerjasama dengan pemerintah Myanmar untuk membentuk HASCO (Humanitarian Assistance for Sustainable Community). Tujuan utama dibentuknya program tersebut ialah untuk penyaluran bantuan kemanusiaan bagi korban konflik pasca kerusuhan di Rakhine tanggal 25 Agustus 2017. HASCO memiliki program kerja selama dua tahun dimulai sejak tahun 2017, yang berfokus pada empat bidang; pendidikan, kesehatan, ekonomi, dan bumanitarian relief (Maulana, 2017).

Bantuan kemanusiaan Indonesia tiba di Myanmar pada tanggal 21 September 2018. Sedangkan bantuan Indonesia terkait pembangunan rumah sakit di Rakhine sudah dimulai pada tanggal 19 November 2017. Bantuan kemanusiaan yang diberikan oleh Indonesia berupa pembangunan rumah sakit di Rakhine dapat terealisasi berkat bantuan masyarakat Indonesia. Biaya pembangunan rumah sakit tersebut merupakan hasil kerjasama pemerintah Indonesia dengan masyarakat Indonesia melalui penggalangan dana (Perdana, 2017).

Dalam kesempatan untuk bertemu dengan pemimpin de facto
Myanmar Aung San Suu Kyi, Menteri Luar Negeri Indonesia Retno Marsudi melakukan negosiasi terkait solusi penanganan kasus ini, melalui formula 4+1. Dalam dialog itu, Indonesia mengingatkan kembali solusi yang diberikan oleh Dewan Penasihat Rohingya yang dipimpin oleh mantan Sekjen PBB Kofi Annan, yang tertuang dalam laporan Dewan Penasehat Rohingya. Negosiasi yang tidak kalah penting adalah solusi yang diberikan Indonesia terkait formula 4+1 poin kelima yakni pentingnya implementasi rekomendasi Laporan Dewan Penasehat Rohingya yang dipimpin oleh Kofi Annan. Negosiasi yang dilakukan Indonesia dan Myanmar terkait formula $4+1$ poin ke lima tersebut, mencapai kesepakatan bahwa Myanmar akan membentuk komite implementasi dan badan penasehat untuk mengawasi implementasi rekomendasi (Tempo, 2017). Dalam prakteknya, Komite ini tidak berjalan dengan maksimal karena tidak adanya keseriusan dari pemerintah Myanmar dan militer Myanmar untuk menyelesaikan krisis kemanusiaan ini.

\section{Kesediaan Bangladesh atas Perlindungan Pengungsi Rohingya}

Negosiasi Indonesia dengan pemerintah Bangladesh pada kunjungan diplomatik tanggal 5 
September 2017, menghasilkan kesepakatan bersedianya pemerintah Bangladesh untuk memberi perlindungan terhadap pengungsi Rohingya dan membuka akses bagi pihak asing untuk memberikan bantuan kemanusiaan terhadap para pengungsi Rohingya yang berada di Bangaldesh. Dalam proses penyaluran bantuan kemanusiaan ke Bangladesh, Indonesia menjalin kerjasama dengan United Nations High Commissioner for Refugees (UNHCR) dan International Organization for Migration (IOM) yang berada di Bangladesh (Kardi, 2017).

\section{KESIMPULAN}

Mengacu pada kasus ini, sikap masyarakat internasional yang menerapkan diplomasi dengan menggunakan ancaman keras yang memojokkan pemerintah Myanmar maupun ancaman embargo tidak mendapatkan hasil yang memuaskan. Di sisi lain, hal ini menjadi kesempatan bagi Indonesia untuk hadir sebagai kawan lama Myanmar dengan diplomasi kemanusiaan. Langkah diplomasi kemanusiaan yangdilakukan Indonesia, meliputi; melakukan komunikasi dengan Pemerintah Myanmar dan Bangladesh serta beberapa pihak asing, sebagai penghubung antara pemerintah Myanmar dan masyarakat internasional, serta melakukan negosiasidengan pemerintah Myanmar dan Bangladesh terkait solusi penyelesaian krisis pengungsi Rohingya ini menghasilkan kepercayaan pemerintah Myanmar terhadap Indonesia, sehingga krisis pengungsi Rohingya akibat konflik pada tahun 2017 dapat diatasi.

Kasus ini menjadi bukti bahwa diplomasi kemanusiaan dapat menjadi instrumen yang tepat dilakukan untuk menangani permasalahan krisis pengungsi. Diplomasi kemanusiaan berhasil diterapkan pada permasalahan pengungsi karena tujuan utamanya adalah menolong para pengungsi sebagai korban konflik. Praktek diplomasi kemanusiaan yang netral dan tidak ikut campur ke dalam urusan politik dalam negeri pihak-pihak yang berkonflik, dapat membangun kepercayaan dari pihak-pihak yang berkonflik itu sendiri. Dengan adanya kepercayaan tersebut, aktor diplomasi kemanusiaan mendapatkan akses pada korban konflik, sehingga masalahmasalah kemanusiaan yang dialami korban konflik dapat segera diatasi.

\section{REFERENSI}

Arungbudoyo, W. (2017) Kronologi Kekerasan di Rakbine Pemicu Eksodus Muslim Robingya (Online). Tersedia di: https://news.okezone.com/read/201 7/08/31/18/1767078/kronologikekerasan-di-rakhine-pemicu-eksodusmuslim-rohingya (Diakses: 5 September 2017).

Asril, S. (2017) Indonesia Mulai Bangun Rumah Sakit di Rakbine, Myanmar (Online). 
Tersedia di:

https://nasional.kompas.com/read/2 017/11/20/15285611/indonesia-

mulai-bangun-rumah-sakit-di-rakhinemyanmar (Diakses: 17 Februari 2018).

BBC. (2017) Bantuan Indonesia untuk Robingya di Bangladesh 'Mulai Dibagikan Hari Ini' (Online). Tersedia di:

https://www.bbc.com/indonesia/am p/indonesia-41302028 (Diakses: 14 Maret 2018).

Bonasir, R. (2015) Mengapa Orang - Orang Robingya Melarikan Diri dari Myanmar? (Online). Tersedia di: https://www.bbc.com/indonesia/dun ia/2015/05/150522_dunia_myanmar _exodus (Diakses: 9 Maret 2018).

Christiastuti, N. (2017) Begini Awal Mula Serangan Besar-Besaran Militan Robingya di Rakbine (Online). Tersedia di:

https://m.detik.com/news/internasio nal/3632173/begini-awal-mulaserangan-besar-besaran-militanrohingya-di-rakhine (Diakses: 7 Februari 2018).

Deutsche Welle. (2012) Ribuan W arga Myanmar Mengungsi (Online). Tersedia di: https://m.dw.com/id/ribuanwarga-myanmar-mengungsi/a16028771 (Diakses: 10 Maret 2018).

Deutsche Welle (DW). (2017) Indonesia Turun Tangan Bantu Robingya (Online). Tersedia di: https://amp.dw.com/id/indonesiaturun-tangan-bantu-rohingya/a40351496 (Diakses: 10 Maret 2018).

Erdianto, K. (2016) Bahas Krisis Rohingya, menlu Retno Akan Bertemu Aung San Suu Kyi (Online). Tersedia di: https://nasional.kompas.com/read/2 016/12/06/11192091/bahas.krisis.ro hingya.menlu.retno.akan.bertemu.aun g.san.suu.kyi (Diakses: 12 Maret 2018).

Ericssen. (2017) Bantuan PBB Diblokir, Nestapa Rohingya Bertambah Parah
(Online). Tersedia di:

https://internasional.kompas.com/re $\mathrm{ad} / 2017 / 09 / 05 / 1832431 /$ bantuan-

pbb-diblokir-nestapa-rohingya-

bertambah-parah (Diakses: 8 Februari 2018).

Ihsanuddin. (2017) Bantu Robingya, Menlu Retno Akan Terbang ke Myanmar

(Online). Tersedia di:

https://nasional.kompas.com/read/2 017/08/30/16594071/1/banturohingya-menlu-retno-akan-terbangke-myanmar (Diakses: 13 Maret 2018).

Iqbal, M. (2017) Menlu Turki Hingga Kofi Annan Telepon Retno Minta RI Bantu Robingya (Online). Tersedia di: https://m.kumparan.com/@kumpara nnews/menlu-turki-hingga-kofiannan-telepon-retno-minta-ri-banturohingya (Diakses: 12 Maret 2018).

Jordan, R. (2017) Di KTT ASEAN, Jokowi: Kita Tak Bisa Berdiam Diri Soal Rakbine State (Online). Tersedia di: https://m.detik.com/news/berita/37 25193/di-ktt-asean-jokowi-kita-takbisa-berdiam-diri-soal-rakhine-state (Diakses: 17 Februari 2018).

Kardi, D.D. (2017) Di Bangladesh, Menlu Retno Bahas Pengungsi Robingya (Online). Tersedia di: https://m.cnnindonesia.com/internas ional $/ 20170906002430$ 106239709/di-bangladesh-menluretno- bahas-pengungsi-rohingya (Diakses: 17 Februari 2018).

Kementerian Luar Negeri Republik Indonesia. (2016) Bantuan Kemanusiaan Indonesia untuk Robingya/Rakbine State (Online). Tersedia di: https://www.kemlu.go.id/id/berita/P ages/bantuan-kemanusiaan-indonesiauntuk-rohingya.aspx [Diakses: 16 Februari 2018).

Kementerian Luar Negeri Republik Indonesia. (2017) Menlu RI Serabkan Usulan Formula 4+1 untuk Rakbine State kepada State Counsellor Myanmar 
(Online). Tersedia di: https://www.kemlu.go.id/id/berita/P ages/Menlu-RI-Serahkan-usulanFormula-41-untuk-Rakhine-Statekepada-State-CounsellorMyanmar.aspx (Diakses: 16 Februari 2018).

Lestari, R. (2017) Indonesia Akan Bawa Konflik Robingya ke KTT OKI dan Sidang Umum PBB (Online). Tersedia di: https://news.okezone.com/read/201 7/09/05/337/1769735/indonesiaakan-bawa-konflik-rohingya-ke-kttoki-dan-sidang-umum-pbb\#lastread (Diakses: 18 Februari 2018).

Maulana, V. (2017) Menlu Retno Luncurkan Aliansi Kemanusiaan Indonesia untuk. Myanmar (Online). Tersedia di: https://internasional.sindonews.com/ newsread/1235597/40/menlu-retnoluncurkan-aliansi-kemanusiaanindonesia-untuk-myanmar1504167196 (Diakses: 17 Februari 2018).

Minear, Larry dan Smith, Hazel. (2007) Humanitarian Diplomacy: Practitioners and Their Craft. Tokyo: United Nations University Press.

Perdana, A.V. (2017) Myanmar Tegaskan Pemulangan Pengungsi Robingya Mulai Januari 2018 (Online). Tersedia di: https://internasional.kompas.com/re ad/2017/12/19/18460791/myanmartegaskan-pemulangan-pengungsirohingya-mulai-januari-2018 (Diakses: 18 Februari 2018).

Pratama, F. (2017) Bertemu Panglima Myanmar, Menlu Minta Militer Hentikan Kekerasan (Online). Tersedia di: https://m.detik.com/news/berita/d3628207/bertemu-panglimamyanmar-menlu-minta-militerhentikan-kekerasan (Diakses: 17 Februari 2018).
Reuters. (2017) Bangladesh Usir Pengungsi Robingya (Online). Tersedia di: https://m.cnnindonesia.com/internas ional/20170830093406-

106238269/bangladesh-usirpengungsi- rohingya (Diakses: 8 Februari 2018).

Suryanto. (2017) Myanmar, Bangladesh Sepakati Pemulangan Pengungsi Robingya (Online). Tersedia di: https://m.antaranews.com/berita/66 0708/myanmar-bangladesh-sepakatipemulangan-pengungsi-rohingya (Diakses: 18 Februari 2018).

Tempo. (2017) 4 Formula Indonesia Untuk Selamatkan Robingya (Online). Tersedia di:

https://nasional.tempo.co/amp/9060 54/4-formula-indonesia-untukselamatkan-rohingya (Diakses: 14 Maret 2018).

Teresia, A. (2017) JK Bahas Robingya Bersama Pemimpin Negara OKI di Sela Sidang PBB (Online). Tersedia di: https://m.kumparan.com/@kumpara nnews/jk-bahas-rohingya-bersamapemimpin-negara-oki-di-sela-sidangpbb (Diakses: 14 Februari 2018). 